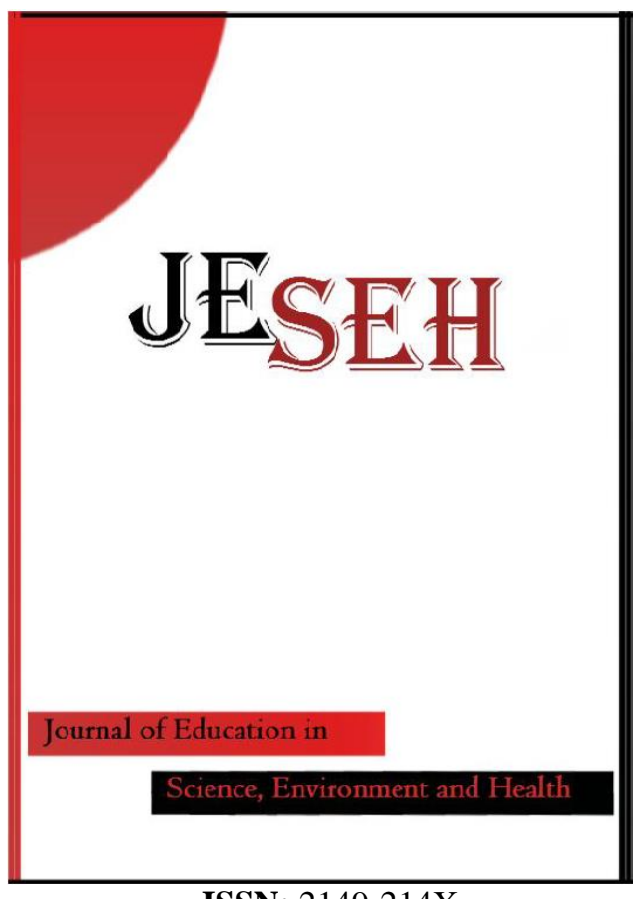

Journal of Education in Science, Environment and Health

$\underline{\text { www.jeseh.net }}$

Candidate Classroom Teachers' Perceptions about being Scientific in the Context of Pseudoscience

Huseyin Es, Halil Turgut

Sinop University

To cite this article:

Es, H. \& Turgut, H. (2018). Candidate classroom teachers' perceptions about being scientific in the context of pseudoscience. Journal of Education in Science, Environment and Health (JESEH), 4(2), 142-154. DOI:10.21891/jeseh.409497

This article may be used for research, teaching, and private study purposes.

Any substantial or systematic reproduction, redistribution, reselling, loan, sub-licensing, systematic supply, or distribution in any form to anyone is expressly forbidden.

Authors alone are responsible for the contents of their articles. The journal owns the copyright of the articles.

The publisher shall not be liable for any loss, actions, claims, proceedings, demand, or costs or damages whatsoever or howsoever caused arising directly or indirectly in connection with or arising out of the use of the research material. 


\title{
Candidate Classroom Teachers' Perceptions about being Scientific in the Context of Pseudoscience
}

\author{
Huseyin Es, Halil Turgut
}

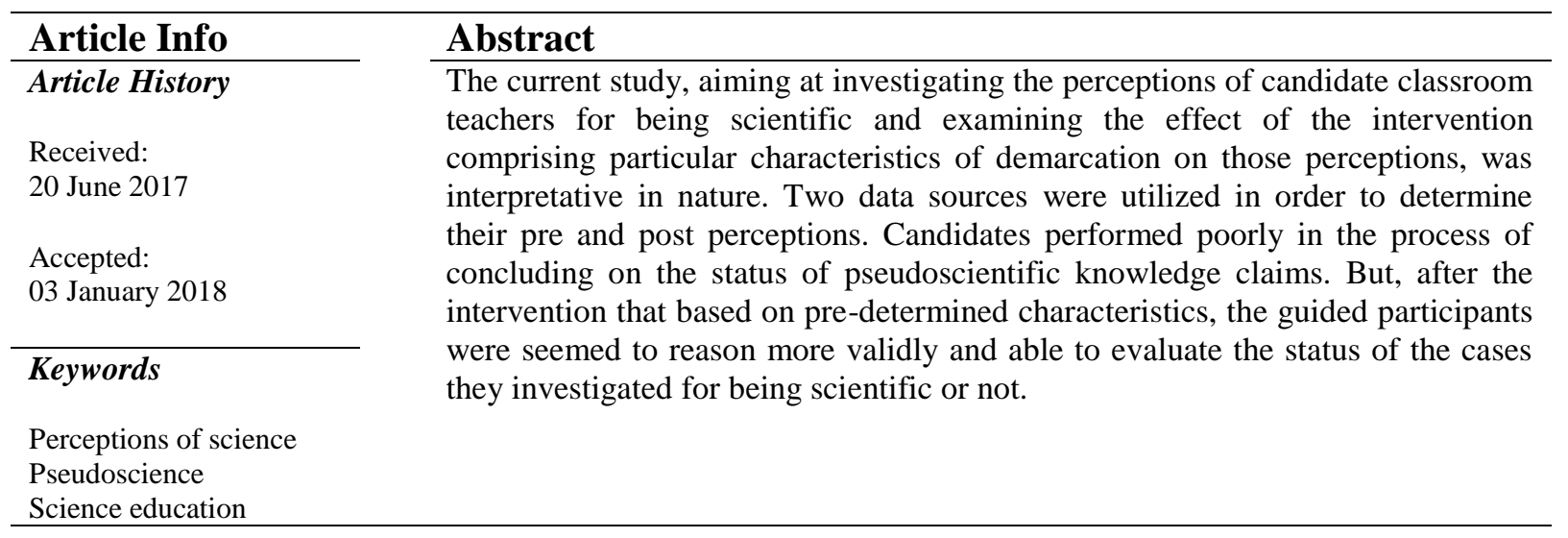

\section{Introduction}

Scientific and technological developments such as genetic copying, journeys to deep inside the space and even colonizing in different planets increase the prosperity level and life quality of human being, thus making science an indispensable part of our social life. It is even suggested that it will not be possible to argue values, socioeconomic issues and objectives of education without considering the role of science (Hurd, 1998). But, it still seems controversial to define science as a way of knowing at least philosophically. Various philosophers and schools of thought such as logical positivists, Popper, Kuhn, Lakatos and Feyerabend had developed their definitions of science and tried to establish boundaries for it but their perceptions with regard to the processes, validity criterions and even credibility of science were seen diverged (Dilworth, 2006; Mahner, 2007; Nickles, 2006). On the other hand, apart from philosophical debates, some researchers tried to reveal general definitions of science in order to construct a common platform of dialogue and cited science as the techniques to have an access to knowledge in a secure way (Feder, 2014) or as the activity of revealing valid/reliable generalizations, explanations that attempt to answer the questions regarding the natural word which are open to criticism (McComas, 1996). The related literature on nature of science (NOS) and the proposed aspects of it can also be viewed in this manner (Gauch, 2009; Lederman, 1998). So talking about science and its common characteristics such as having empirically based data and etc. across the well-known scientific disciplines and constructing boundaries for science seems unproblematic, at least for scientists (Bauer, 2001; Derry, 1999).

The demarcation issue should be tackled as the distinction of science from pseudoscience or nonscience, but the extensive meanings of these concepts must be clarified. The concept of nonscience has been clarified by the use of fields such as the humanities disciplines, arts, religion and literature (Laudan 1983; Mahner 2007). These fields are not usually considered scientific; also their ontological and epistemological presuppositions vary from those of the natural sciences (Turgut, 2011). Hence nonscience is to be understood as an inclusive concept involving various fields of knowledge which do not allege to be scientific. Pseudoscience is quite different that is, disciplines in this category often claim to be scientific, although they do not meet the various standards set by science philosophers (Preece and Baxter 2000).

However, when the issue of being scientific is handled in the context of pseudoscientific knowledge claims and disciplines, the criteria to be used become fuzzy. The issue of demarcation of science and pseudoscience requires criteria that would be valid for all disciplines of science without any debate which seems to be not achieved yet (Gillies, 1998; Nickles, 2006). Many of the criteria proposed by various philosophers of science were marked as either too narrow or too broad, or found to be generally unsatisfactory. Indeed, some have argued about the impossibility of identifying certain criteria for a clear-cut demarcation of scientific areas of inquiry from nonscientific ones (Laudan 1983; Mahner 2007). It is widely argued that to define science in a simple way or to draw the borders of science with strict lines cannot be possible because of the complexity of 
scientific enterprise (Turgut, 2011). For some instances, controversies (as a processes) themselves would be more valuable than their results. Then the problem is not just related with the criteria of demarcation to be used; (i) recent inquiries and data can change the opinions and, (ii) some psychological factors can much more be determinant than the accepted criteria. There exist some historical cases for the first one, such as acupuncture, which was previously considered as pseudoscientific (Allchin, 1996), but then was partly accepted as scientific after particular controlled experiments performed (Ulett, Han \& Han, 1998). The well-known pseudoscientific astrology can be viewed for the second one, dealing with the effect of heavenly bodies on human psychology and hence claims the tasks of astronomy and psychology, which still seems accepted as scientific in many circles (Francis \& Robbins, 2007; Lundström, 2007; Losh \& Nzekwe, 2011). On the other hand, in order to overcome the difficulties at least partially in the context of the issue of demarcation, the approach of Smith and Scharmann (1999) can be adopted since the proposed criteria are debatable. In that approach, the problem is seen as 'What are the features that make the field of research more scientific or less scientific?' instead of 'Is this field of research scientific or not?' by rejecting the idea of strict demarcation. Smith and Scharmann (1999) provided a reflective synthesis and draw some implications of these proposals for teacher preparation. Their suggestions can be thought as a continuous distribution that there is science, on one side, and non-science, on the other. In addition to this, they proposed the characteristics that make a field of study more scientific or less scientific. They classified the characteristics that make a field of study more scientific as "The Objects and Processes of Study" and "Values of Science". On the other hand the same researchers stated that "Espousing a Theological Position", "Valuing Authority over Evidence", and "Fideism" as the characteristics that make a field of study less scientific. Based on the literature about the demarcation problem, it is considered that Smith and Scharmann's approach is more suitable than drawing the borders of science with strict lines. Additionally, individuals are faced with various pseudo-scientific claims and need to make a decision or judgement about these claims. So using some characteristics or criteria is an inevitable necessity in the demarcation process when considering the frequency of encountering pseudoscientific claims in daily life. Therefore, teaching the characteristics of science to learners is better than drawing the borders of science. Accordingly, in the current study we presented some characteristics of science to the participants to use in the demarcation.

The astrology type instances indicate that the credibility and public prestige of science leads to the emergence of many types of pseudoscientific claims in the guise of science that are presented especially with the label of logy as a marketing tactic (Turgut, 2009; Turgut, Akçay \& İrez, 2010; Turgut, 2011; Uslu, 2011). Therefore, the problem of pseudoscience is not just a philosophical and/or technical issue; it has some public and economic dimensions that are to be considered (Nickles, 2006). It should be asserted that to demarcate scientific theories or research from pseudoscientific ones and conspiracy theories is crucial for also sociological motives (Turgut, 2009; Turgut, Akçay \& İrez, 2010; Uslu, 2011). The public and sociological aspects of the issue require introducing pseudoscience to society at least conceptually. As a threshold matter, without ignoring the philosophical difficulties in formulating the strict criteria for demarcation, the phrase of pseudoscience can be presented in a simple way as a wholesome of the claims deprived of scientific proofs and cogency even though it appears with the claim of being scientific (Shermer, 1997). In other words, as mentioned above the pseudoscientific claims are proposed to be scientific by their proponents but they are mostly regarded as not scientific since they do not meet the scientific standards such as to be verifiable either experimentally or theoretically (Finn, Bothe \& Bramlett, 2005; Jahoda, 1969; Preece \& Baxter, 2000).

As stated above, since pseudoscientific claims are presented with the label of being scientific, they hide behind the prestige of science and therefore it becomes difficult for individuals to determine them (Tseng, Tsai, Hsieh, Hung \& Huang, 2014). Related research showed that many pseudoscientific claims such as spacemen, telekinetic, astrology, lucky numbers and etc. are being approved by the society at non-ignorable level (Moore, 2005; National Science Board [NSB], 2006; Tobacyk, Milford, 1983) and media is assumed to play an important role in that approval by presenting them in an exciting fashion (Nickles, 2006). So, it is of crucial importance to train scientifically literate individuals who had developed qualified perceptions with regard to the pseudoscientific claims and the aspects of them which do not meet the standards of science (Turgut, 2009). The visions of modern educational reform movements and Elementary Science Education Curriculum of Turkey (Republic of Turkey Ministry of National Education [MEB], 2013) can also be interpreted in that way; scientific literacy was not put forward as a requirement for just particular professional groups and scientists, but aimed for all society and raising scientifically literate individuals was regarded as one of the significant objectives of science education.

The scientifically literate citizens of contemporary societies are expected to be aware of the scientific concepts, use scientific principles in an effective way, discuss scientific subject matters, make intended decisions and learn about the nature of scientific knowledge, while they are interacting with their environment (Murcia \& Schibeci, 1999; Ryan \& Aikenhead, 1992; Ryder, 2001). Developing those intended competencies require 
reflecting upon the learning environments and the search of meaningful contexts to be governed in order to provide individuals to practice them. Previous research performed with candidate teachers of science indicated that the context of the issue of demarcation of science and pseudoscience could be used effectively in this sense since standards and particular aspects of science were viewed in the scope and individuals were required to conclude with the use of the proposed criteria (Turgut, 2009; Turgut, Akçay \& İrez, 2010; Turgut, 2011). Turgut (2009) pointed out that the science teacher candidates seem to lack skills necessary to examine sciencepseudoscience difference critically which results in deficiencies in such an important demarcation. Also Turgut, Akçay \& İrez, (2010) indicated that based on the results of their study conducted with 38 elementary science teacher candidates, the course design framed on demarcation of science from pseudoscience instead of a traditional NOS course involving broad discussions on all aspects of science could be used effectively in NOS instruction. In addition to these, Turgut (2011) suggested that a learning intervention based on the issue of demarcation of science from pseudoscience proved an effective instructional strategy, which a majority of teacher candidates claimed to plan to use in their future teachings. However, science courses of the Turkish Science Education Curriculum are planned from $3^{\text {rd }}$ grade up to $8^{\text {th }}$ grade and they are taught by classroom teachers at $3^{\text {rd }}$ and $4^{\text {th }}$ grades. Science teachers become a part of the curriculum at just $5^{\text {th }}$ grade which means that students experience initial formal science practices with their classroom teachers. So, the role of classroom teachers seems crucial as the first step in the science curriculum (Akerson, Buzzelli \& Donely, 2010) in the route of constituting an intellectual basis for perceptions of science in the scope of scientific literacy and related competencies in the early ages.

\section{Research Questions}

Given the importance of constituting an intellectual basis for individuals' perceptions of science in their early ages and the crucial role of classroom teachers in that process, the study was focused on Turkish pre-service classroom teachers' conceptions of being scientific in the context of pseudoscientific claims. It was asserted that in order to guide their students in developing informed perceptions of science, the classroom teachers initially themselves must have the required competencies. So the research questions of the study were as follows:

1) How do Turkish pre-service classroom teachers perceive "Being Scientific?"

2) How does the intervention based on the pre-determined characteristics of science affect Turkish pre-service classroom teachers' perceptions of "Being Scientific?"

\section{Method}

The current study, aiming at firstly investigating the perceptions of candidate classroom teachers for being scientific and then examining the effect of the intervention comprising particular characteristics of demarcation on those perceptions, was interpretative in nature. The methodology of the research was presented in terms of participants, intervention, data sources and analysis process under separate headings in detail below.

\section{Participants and Course Context}

The participants of the study were determined by purposeful sampling technique (Creswell, 2012) since the issue of the research was perceptions with regard to being scientific that questioned in the context of various pseudoscientific cases which requires having basic terminology of science to be understood. The primary criterion in the sampling process was to take fundamental science courses (physics, chemistry and biology) of the undergraduate classroom teacher education curriculum. Therefore, the research was confined to third grade teacher candidates in the context of the compulsory Science and Technology Education course that taught by one of the researchers for three hours a week. After the target group was determined, the secondary criterion of the sampling process was set as being volunteer to express perceptions and views with regard to the related issue. For this, an open-ended questionnaire developed by the researchers as data collection tool was introduced to 66 third grade candidate classroom teachers. They responded the questionnaire individually and after the overall analysis of their answers for content and explicitness, 60 of the candidates (26 males and 34 females, ages ranging from 20 to 25 ) were assigned to constitute the study group.

After the participants of the study determined, the researchers introduced the content and the objectives of the course (Science and Technology Education) to them and shared only the name of the cases. Then, the participants were asked to choose one of the cases from the pre-determined list comprising astrology, reflexology, healing stones, acupuncture, ufology, graphology, parapsychology and iridology in order to search 
for their fundamentals and basic claims for a period of one week. Multiple cases were preferred instead of just one, since it was aimed to allow participants to perform research into the subject matters that they were interested in. Each case was investigated by 4 to 10 participants voluntarily and to prevent any guidance, they were asked to investigate what the subject matter was, what kind of process it had, where and for what purposes they were used, by whom and when they were used. In order to prevent a guidance before the course, they were not asked to examine the status of the cases for being scientific or not and any discourse was not provided to them by the researchers before their research. Because we were wondering how they would evaluate being scientific of the cases when they searched for it on their own without any guidance.

The participants performed their research and prepared individually written reports with regard to the assigned cases. Then they were asked to conclude on the status of the cases and claims for being scientific or not with their rationales and warrants. As the next step, they were grouped according to the cases that they searched (e.g. the ones who searched astrology were Group 1, reflexology were Group 2 etc.) to discuss and re-evaluate the status of the cases within those groups. Following the group discussions, the characteristics of science (consistency, observability, being natural, predictability, testability, tentativeness - CONPTT) cited in the work of Dickhaus (1999) were presented one by one to participants and discussed with them in the class. In the presentation of the instruction about the meaning of the characteristics, question-answer and expository teaching methods were used by the researcher in the course of three lessons. In this process, some tasks were carried out and the assigned cases were partially examined by the participants through the presented characteristics. The intervention was comprised of three hours in addition to the research period and at the end of it, "Worksheet: Is It Science? Is It a Scientific Statement?" was applied to participants.

\section{Data Sources and Analysis}

In this research, two data sources were utilized in order to determine participants' pre and post perceptions about being scientific. The initial data source was a form that was used as pre-test in order to determine the participants' initial perceptions for being scientific. It was utilized after the participants completed their search for individually assigned cases (i.e. reflexology, acupuncture etc.) and therefore collected information with regard to their fundamentals. In the first question of the form, participants were asked to conclude for the case if it is being scientific or not and then in the second question they were invited to express their warrants and rationales. Based on their rationales and presented warrants, the characteristics that participants used in the process of evaluating any claim for its status of being scientific or not were tried to be determined. The data obtained through this form were analyzed qualitatively. In the analysis process, initially, the answer sheets of the participants were representatively renamed (as an example, the sheet of the first candidate teacher investigating the subject matter of astrology was renamed as A1). Then, the answers of each participant were reviewed in a way that they could allow to evaluate the expressions and particularly repeating concepts without breaking the unity inside them. For this, each answer sheet was read separately in order to code the potential concepts and thematic structures in short and the coding process was based on either just words or whole sentences, paragraphs (Bogdan \& Biklen, 2007; Gay, Mills \& Airasian, 2006).

The second data source of the research that was utilized to determine post perceptions of the participants for being scientific after the brief intervention was "Worksheet: Is It Science? Is It A Scientific Statement?". It was developed by Dickhaus (1999), adapted to Turkish by İrez and Turgut (2012) and constructed on a group of predetermined characteristics such as consistency, observability, being natural, predictability, testability and tentativeness (CONPTT). With the help of that form, the participants were asked to re-evaluate the cases that they searched and evaluated with their own characteristics before the intervention. They filled the form and concluded on the status of the assigned cases for being scientific or not. In this process, the related cases meeting all the characteristics of science were qualified as scientific while those falling short in one or more of the characteristics of science were labelled as proto-scientific. Besides that, the cases that do not meet the characteristics despite having the claim of being scientific were classified as pseudoscientific. The category of non-scientific was also provided for the ones that do not meet the characteristics of science and do not have any claim of being scientific differently from the pseudoscientific ones.

\section{Findings}

The findings of the study presented in this section were organized according to the research questions and data collection procedures detailed previously. Hence, firstly the participants' initial perceptions with regard to status of assigned cases were given. Then the characteristics of science that they used in evaluating the cases, the 
within group discussions and their post perceptions about the status of the cases for being scientific were viewed.

\section{Participants' Initial Perceptions about the Status of Assigned Cases}

After they performed research on the fundamentals and basic claims of the assigned cases, the participants tried to conclude about the status of them for being scientific or not. The first question of the initial data source, the open ended form, was used for this aim and without any interpretation the participants answered it by labeling the case they searched as scientific or not. Some of the participants strictly labelled their cases as either scientific or pseudoscientific whereas some of them talked about the possibility of being scientific. The perceptions of participants and their distribution along the cases were presented in Table 1.

Table 1. Participants' initial perceptions about the status of assigned cases

\begin{tabular}{|c|c|c|c|c|c|c|c|c|c|}
\hline & 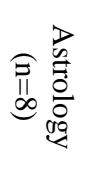 & 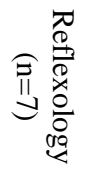 & 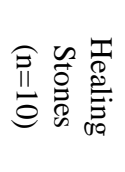 & 兽总 & 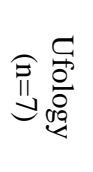 & 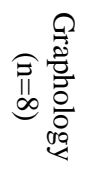 & 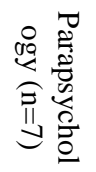 & 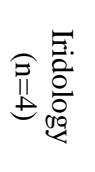 & $\overrightarrow{0}$ \\
\hline Scientific & & 4 & 2 & 5 & 1 & 4 & 1 & 4 & 21 \\
\hline Possible & & 1 & & 1 & & 2 & & & 4 \\
\hline Pseudoscientifc & 3 & & & & & & & & 3 \\
\hline Non-scientific & 5 & 2 & 8 & 3 & 6 & 2 & 6 & & 32 \\
\hline
\end{tabular}

As given in Table 1, three participants out of 8 labelled astrology as pseudoscientific while five of them pointed out that it is non-scientific. It was not accurate that they were aware of the difference between pseudoscience and non-science but none of them qualified astrology as scientific. It was seen that an important portion of the participants investigating reflexology (4 out of 7), acupuncture (5 out of 9) and graphology (4 out of 8) regarded that these cases were within the limits of science. In addition, all of the participants who searched the case of iridology labelled it as scientific. On the other hand, the great majority of the participants examining healing stones (8 out of 10), ufology (6 out of 7) and parapsychology (6 out of 7) evaluated them out of scientific limits and hence non-scientific.

\section{Participants' Initial Perceptions about the Characteristics of Science}

In the second question of the initial data source, the open ended form, the participants were asked to justify their conclusions with regard to the status of the cases for being scientific or not that they investigated. Their responses were analyzed for the characteristics they presented in evaluating the assigned cases and the findings revealed were given in Table 2.

Table 2. Participants' Initial Perceptions about the Characteristics of Science

\begin{tabular}{|c|c|c|c|c|c|c|c|c|}
\hline 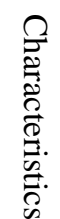 & $\begin{array}{l}> \\
0 \\
0 \\
0 \\
0 \\
0 \\
90\end{array}$ & 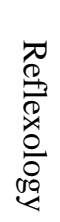 & 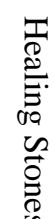 & $\begin{array}{l}\stackrel{D}{O} \\
ٍ \\
\Xi \\
\Xi \\
\Xi \\
0\end{array}$ & 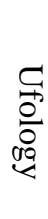 & 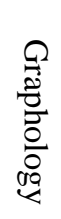 & 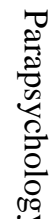 & 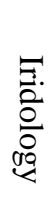 \\
\hline
\end{tabular}

\begin{tabular}{llllllllll}
\hline Being Natural & 3 & 3 & 6 & 3 & 4 & 2 & 8 & 1 & 30 \\
\hline Verifiable & 4 & 2 & 7 & 5 & 6 & 1 & 2 & 1 & 28 \\
\hline Observability & 4 & 6 & - & 4 & 3 & - & 3 & 2 & 21 \\
\hline Consistency & 3 & 3 & 2 & 4 & 1 & 1 & 4 & 1 & 19 \\
\hline Expert Opinion & 1 & 5 & 3 & 7 & 4 & 1 & 4 & 1 & 26 \\
\hline Institutionalism & 3 & 1 & 5 & 3 & 1 & 3 & 1 & - & 17 \\
\hline Terminology & - & 2 & 2 & 2 & 2 & 3 & - & 2 & 13 \\
\hline Persistency & - & 2 & 3 & 2 & - & 1 & 1 & - & 9 \\
\hline
\end{tabular}


It was seen that participants proposed several characteristics of science in the scope of the cases they investigated. Among these, ontological ones were in the forefront such as being natural, verifiable and observable. In addition participants also cited psychological characteristics such as expert opinion and rational/methodological characteristics such as consistency. The distribution of those characteristics across the cases indicated that being natural, verifiable and consistent were offered for all by the participants.

The criterion which was mostly cited $(\mathrm{f}=30)$ in evaluating the status of knowledge claims for being scientific was being natural. With that criterion participants focused on the ontology of the entities which were mentioned as the subject of the investigated case and limited the boundaries of science and hence being scientific to physical universe. In accordance, they also indicated being verifiable $(\mathrm{f}=28)$ and observable $(\mathrm{f}=21)$ as characteristics of science:

Such things as changing of dimension by human being, reading them mind etc. are out of material today and things out of material are not a science but metaphysics (P 5).

Astrology examines the effects of celestial bodies on human character and it cannot be proved. We cannot prove the effects of celestial bodies on human character (A 3).

It is scientific if a spot is minimized in the eye of a human being and his disease is known, when we have a look at the symptoms of the diseases depending on the spot and the severity of it is decreased (I 2).

The approach of the participants with regard to the issue of being scientific was seen consistent at ontological level; they provided being natural, observable and verifiable. Although they did not detail the issues of being verifiable and observable in direct or indirect forms, they explicitly reflected the boundary and methodology of science.

As being natural and verifiable, participants also cited the criterion of being consistent $(\mathrm{f}=19)$ in all the cases. By consistency some of the participants referred to methodological procedures such as yielding same results in repeated treatments whereas some others mentioned being free of self-contradictions:

Acupuncture treatments cause varying outcomes for different people. The effects of the treatment are not observed as they asserted for all the patients (AC 6).

It is not rational and reasonable. Why people should arrange their lives according to astrology? It has contradictory aspects. Also astrologers contradict each other and astrology does not seem consistent (A 4).

It was seen that participants offered the criterion of consistency partially in parallel with ontological ones. Some of them claimed to be repeatable and the requirement of yielding the same results in repeated practices by independent researchers as criterion of being scientific. In addition some of them underlined the rational/logical unity and consistency of arguments that provided by the proponents of the investigated cases.

Another group of characteristics participants provided were based on the notion of authority. They cited expert opinion $(\mathrm{f}=26)$, institutional approval $(\mathrm{f}=17)$ and use of scientific terminology $(\mathrm{f}=13)$ in the process of concluding the status of the cases they investigated for being scientific or not. The common factor in those characteristics was seen to be their social emphasis, prestige and connotation of authority on people and hence participants:

There are not enough experts in this field. The ones in the field are trained in very short time and it is not enough to become a specialist. They are not educated in the universities. Many doctors and academicians do not think that it is scientific (R 2).

If it were scientific, modern medical institutions would approve and not try to produce drugs for the diseases instead of healing stones. They would easily heal the patients with those stones (HS 7).

When we look at the formula of active elements of healing stones, we see scientific, chemical components. In addition their origin is explained scientifically by the movements of the magma (HS 10). 
The concept of expert was associated with academic titles or diplomas by participants and hence having formal education on related topics was seen as requirement by them. Institutional approval was also thought in parallel and journals, university departments or organized congresses were offered with the idea of authority behind. In addition the prestige of widely accepted scientific terms and concepts were seen to be in their agenda because of their natural evocation of science.

An additional criterion which was presented by a group participants $(\mathrm{f}=9)$ for the status of knowledge claims for being scientific or not was persistency. The historical background and discourses ever since ancient times with regard to the fundamentals of the investigated cases were seen to provide credit for the participants:

While searching the basics of graphology, I considered that the history of it goes back to the antiquity. A practice which continues to exist since ancient times would be scientific. If it was not scientific it would be denied (G 1).

It was seen that participants presented the criterion of persistency with the notion of being surviving for long periods of time and resisting to counter arguments successfully which meant being valid and hence scientific. Their approach was based on the assertion that just valid and reliable claims would proceed in the history whereas the ones that do not meet those qualifications would be denied inevitably.

\section{Participants' Perceptions Following Group Discussions}

After the individual evaluations were performed and reported by the participants, with regard to the status of the cases for being scientific or not, they were grouped according to the cases investigated. Within groups, participants shared their own opinions with other members and discussed the status of the common cases they investigated with their warrants. Following group discussions, participants' perceptions about the cases and characteristics of science were reviewed. It was seen that any change was not observed in the evaluations of the participants investigating the cases of astrology, reflexology, healing stones and iridology. However, a participant claiming that ufology is scientific changed his mind and labelled it as being out of science after within group discussions:

It is not scientific as the existences of UFOs have not been proven, there is no official proof and no empirical observation has been carried out in this sense (U 2).

It is likely to see that the characteristics leading to the change in the ideas of that participant were being observable and verifiable, hence to be proved. Similarly, a participant investigating the case of graphology and once having a claim that it is scientific changed his mind and then expressed graphology as being out of science:

It is not scientific since there is versatility in the tools and materials used in writing, in surrounding and how graphologists examine it (G 2).

As for the expression of the participant, the criterion leading to a change in his idea was consistency. Being consistent was also one of the characteristics for a participant who changed his mind with regard to the status of parapsychology:

The subject matter of science is material but parapsychology has a content of metaphysics. There is a problem of repetition in the studies carried out. The studies carried out have not been supervised enough and have not been documented (P 6).

It was obvious that the participant changed his mind in line with the characteristics of being natural and consistent. In addition, a participant regarding acupuncture as possibly scientific beforehand changed his mind and claimed that it is within the limits of science after group discussions:

It is within the science of medicine. It is a healing applied by trained experts. The application fields and rules of acupuncture were determined with the regulation of Official Gazette by the Ministry of Health in Turkey (AC 6).

It was seen that the participant altered his view in accordance with the characteristics of institutional approval and expert opinion. Based on those presented above, it could be stated that participants persist on their perceptions about the status of the cases for being scientific or not to a great extent in group discussions. Just 
four participants out of 60 changed their minds and the characteristics they used in that process were mainly ontological and rational/methodological ones.

\section{Participants' Post Perceptions about the Status of Assigned Cases}

As presented in the section of course context, after group discussions performed, the characteristics of science (CONPTT) cited in the work of Dickhaus (1999) were provided to participants and they discussed the cases in class with the help of those characteristics. At the end of this process they individually filled the "Worksheet: Is It Science? Is It A Scientific Statement?" form and concluded the status of the case they investigated for being scientific or not. The findings obtained through the analysis of those worksheets were given together with the findings of first questionnaire and group work in Table 3 in order to interpret the possible changes across the whole process.

Table 3. Participants' post perceptions about the status of assigned cases

\begin{tabular}{|c|c|c|c|c|c|c|}
\hline & & Pseudoscientific & Undecided & $\begin{array}{c}\text { Proto- } \\
\text { Scientific }\end{array}$ & Scientific & $\begin{array}{c}\text { Non- } \\
\text { Scientific }\end{array}$ \\
\hline \multirow{3}{*}{ Astrology } & First View & 3 & - & - & - & 5 \\
\hline & Group-work & 3 & - & - & - & 5 \\
\hline & Final View & 8 & - & - & - & - \\
\hline \multirow{3}{*}{ Reflexology } & First View & - & 1 & - & 4 & 2 \\
\hline & Group-work & - & 1 & - & 4 & 2 \\
\hline & Final View & 6 & - & 1 & - & - \\
\hline \multirow{3}{*}{ Healing Stones } & First View & - & - & - & 2 & 8 \\
\hline & Group-work & - & - & - & 2 & 8 \\
\hline & Final View & 8 & - & 2 & - & - \\
\hline \multirow{3}{*}{ Acupuncture } & First View & - & 1 & - & 5 & 3 \\
\hline & Group-work & - & - & - & 6 & 3 \\
\hline & Final View & 3 & - & 5 & 1 & - \\
\hline \multirow{3}{*}{ Ufology } & First View & - & - & - & 1 & 6 \\
\hline & Group-work & - & - & - & - & 7 \\
\hline & Final View & 7 & - & - & - & - \\
\hline \multirow{3}{*}{ Graphology } & First View & - & 2 & - & 4 & 2 \\
\hline & Group-work & - & 2 & - & 3 & 3 \\
\hline & Final View & 8 & - & - & - & - \\
\hline \multirow{3}{*}{ Parapsychology } & First View & - & - & - & 1 & 6 \\
\hline & Group-work & - & - & - & - & 7 \\
\hline & Final View & 7 & - & - & - & - \\
\hline \multirow{3}{*}{ Iridology } & First View & - & - & - & 4 & - \\
\hline & Group-work & - & - & - & 4 & - \\
\hline & Final View & 1 & - & 3 & - & - \\
\hline \multirow{3}{*}{ Total } & First View & 3 & 4 & - & 21 & 32 \\
\hline & Group-work & 3 & 3 & - & 19 & 35 \\
\hline & Final View & 48 & - & 11 & 1 & - \\
\hline
\end{tabular}

As given in Table 3, all of the participants $(n=8)$ investigating the case of astrology concluded that astrology is a pseudoscience at the end of the process. Although none of them qualified astrology as scientific previously, it was seen that the ones who labelled it as non-scientific $(n=5)$ shifted their terminology then to being pseudoscientific. Similarly, the majority of the participants examining the case of reflexology $(n=7)$ decided that it is pseudoscientific at the end of intervention. Four participants who thought reflexology as scientific and two participants who thought reflexology as non-scientific concluded that it is pseudo-scientific. For the case of healing stones, the great majority of the participants $(n=8)$ came to the point that it is pseudoscientific whereas two of them indicated that it could be proto-scientific. It was obvious that the ones $(n=2)$ claiming healing stones as scientific gave up their opinion. One of the participants (out of 6) investigating the case of acupuncture persisted in his view that it is scientific while rest of them $(n=5)$ regarded acupuncture as proto-scientific. Three participants in this group once regarded it as non-scientific then claimed that pseudoscience is the right concept to define acupuncture. All of the participants investigating the cases of ufology $(n=7)$, graphology $(n=8)$ and parapsychology $(n=7)$ regarded them as being pseudoscientific in their final view. It was seen that most of the participants investigating ufology and parapsychology changed their views from being non-scientific to pseudoscientific. The participants' perceptions with regard to the case of iridology who previously indicated that 
it is scientific were also shifted but most of them ( $\mathrm{n}=3$ out of 4 ) did not labelled it as being pseudoscientific. Instead, they concluded that it could be viewed as proto-scientific.

To sum up, it was seen that participants' perceptions with regard to the status of the cases they investigated for being scientific or not were differed slightly along with group discussions. Just four participants (out of 60) changed their minds and 19 participants persisted in their views about the status of the cases that they are being scientific. However, a clear distinction became apparent after the intervention performed in the class that based on the pre-determined characteristics (CONPTT). Just one participant remained with the perception of being scientific (for the case of acupuncture) and nearly all the participants who claimed the cases they investigated to be non-scientific modified their perceptions to being pseudoscientific. In addition, it was determined that some of the participants $(n=11)$ encountered the concept of being proto-scientific after the intervention. Similarly, while most of the participants did not cite the concept of being pseudoscientific previously (comprising also the perceptions after group discussions) except for astrology, a great many participants $(\mathrm{n}=48)$ changed their mind and eventually regarded the cases they investigated in the context of pseudoscience.

\section{Discussion and Conclusion}

Depending on the findings of the study, it is likely to see that an important portion of the participants $(n=21)$ initially regarded the cases they investigated as being scientific and some of them $(n=4)$ thought them as possible to be scientific. It reveals that even though some of the candidate teachers investigated that subject matter, they were not able to make a detailed reasoning. Such a result was in compliance with research indicating that various pseudoscientific claims as telekinesis, astrology, lucky numbers, or so have considerably been approved by the community (Tobacyk \& Milford, 1983; National Science Board [NSB], 2006; Moore, 2005), expected reasoning skills cannot be used when encountered with paranormal claims (Wang \& Lin, 2005) and even individuals having education in science could not apply scientific knowledge and skills adequately in the process of evaluating pseudoscientific claims (Afonsoa \& Gilbert, 2010; Johnson \& Pigliucci, 2004; Losh \& Nzekwe, 2011; Walker, Hoekstra \& Vogl, 2002). The approval of those pseudoscientific claims by the community and educated individuals such as university students was warranted partly with the impact of television programs (Tseng, Tsai, Hsieh, Hung \& Huang, 2014). Also Mugaloglu (2014) indicated that learners are accepted existing pseudoscientific beliefs because of exposing to alternative constructions through social negotiation than to furthering their appreciation of science. However, it is well known that believing in pseudoscientific claims has mediate and immediate harms (Lindem, 2014) and to develop educational practices in order to create public awareness against them is crucial. For instance, Sagan (1996) expressed that ex US President Ronald Regan and his wife consulted to an astrologist because of their private and social problems which would cause possible negative effects on American community.

On the other hand, it was seen that just the participants investigating astrology regarded their case initially as being either pseudoscientific or non-scientific and hence none of them labelled it as being scientific. This finding was seemed in contrast with research carried out by citizens (Losh, Tavani, Njoroge, Wilke \& Mcauley, 2003), teachers (Kallery, 2001) and candidate teachers (Turgut, 2011) since they revealed that there is a widespread belief for the status of astrology as being scientific. So that, Sugarman, Impey, Buxner, \& Antonellis, (2011) indicated astrology is accepted being scientific by individuals who have strong performance on science knowledge indicators. However, when it was realized that participants searched related literature and viewed the increased popular/explicit claims identifying astrology as being pseudoscientific, it was thought as reasonable since just some of those participants $(n=3)$ used the expression of pseudoscience. The issue that why rest of the participants ( $\mathrm{n}=52$ for other cases in total) did not cite pseudoscience would also be questioned for the sources they viewed but it can also be mentioned that majority of the participants used the phrase of nonscientific in their initial conclusions.

In terms of the findings of the study, participants were seen to put emphasis on ontological, methodological and psychological characteristics such as being natural $(\mathrm{f}=30)$, verifiable $(\mathrm{f}=28)$, observable $(\mathrm{f}=21)$, consistent $(\mathrm{f}=19)$ and persistent $(\mathrm{f}=9$ ) while investigating the status of any claim for being scientific or not based on their individual research. The overall evaluation of that profile revealed that participants mainly focused on empirical aspects of science with the notions of being natural, observable, and verifiable in accord with various research results. For instance, Sperandeo (2004) pointed out that a great majority of physics teachers regarded physics as an accumulation of observation and explanation that was gathered in order to be proved and Tsai (2002) determined that a great majority of science teachers' views about science were based on realist perspective. Ayvaci and Er Nas (2010) indicated that scientific knowledge is asserted to be achieved just through experimental proving by half of the science and technology teachers who participated in their study and Turgut 
(2009) expressed that although candidate teachers of science were seemed to perceive the dialectic of the controlled experiments in science, they had some misconceptions regarding the meaning of experiments in the formation and testing of scientific knowledge. Related research showed that similar perceptions were also observed in the forms of absolute knowledge based on experimental method, developing knowledge through process of proving and assumption of objective epistemology (Hofer, 2000; Roth \& Roychoudhury, 1994). Nevertheless, if the notion of the improvability of the hypothetic theories (Martin, 1994) and basic presuppositions of modern science such as "objective external reality" and "causality" considered (Suchting, 1995), it can be claimed that the current perceptions of the candidates remained limited with traditional science paradigm. Those results obtained in related research in accordance with the ones in this study can be argued to be based on the fact that students perceive science mostly through the course books, teachers and laboratory practices in which the conception of science is limited to its experimental aspect and process of proving (Turgut, 2009; Ayvac1, Er Nas, 2010).

It was also found that some of the participants assumed expert opinion ( $\mathrm{f}=26$ ), institutional approval ( $\mathrm{f}=17$ ), use of scientific terminology $(\mathrm{f}=13)$ and being persistent in history $(\mathrm{f}=9)$ to be determinant for them in evaluating the status of knowledge claims for being scientific or not. It is known that pseudoscientific claims are supposed to be scientific by their proponents and various tactics are used by them in order to reinforce that conception even though those claims do not meet scientific criteria (Shermer, 1997). In this study, it was seen that the assertion of the approval of experts or institutions, inclusion of some scientific terms and having a long history back to ancient times caused to raise the perception of being scientific for the cases investigated in some of the participants' minds naively. That result was obvious to see the importance of psychological criteria for some of the participants either based on the notion of authority or the belief that true one survives in the history, despite the ones that indicate informed views such as being consistent $(f=19)$ and natural $(f=30)$.

Another striking result that revealed in this study was the ineffectiveness of the unguided group discussions, performed in the class, in adopting the perceptions of participants. Just three candidate teachers revised their opinions about the status of the cases they investigated from being scientific to non-scientific and one from undecided to scientific through the discussions within groups after they reflected on mostly cited characteristics of being verifiable, observable, consistent and natural. On the other hand, a considerable alteration was determined in the perceptions of participants about the status of cases they investigated following the intervention performed in the class by one of the researchers that based on pre-determined characteristics of CONPTT. Initially, an important portion of the participants $(n=21)$ thought that their assigned cases were scientific whereas at the end of the process just one participant seemed to persist in his view. In addition, the participants $(n=11)$ who did not previously mentioned the concept of proto-science introduced that concept after the intervention, particularly for the status of acupuncture. Similarly, it was seen that just three participants used the concept of pseudoscience in their evaluations before the intervention but then great majority of the participants $(n=48)$ were able to cite it accurately in their worksheets for the cases they investigated. In fact, those participants were previously seen to adopt the concept of non-science for the cases and could not differentiate the non-scientific from pseudoscientific while labelling the claims as being out of science. So, it can be asserted that an important gain for the participants in this research was to develop awareness about the difference between pseudoscientific and non-scientific disciplines since the former is sometimes used pejoratively instead of the latter for various claims (e.g. religious ones) in some circles (Turgut, 2011).

To conclude on the status of various claims, for if they should take place within limits of science and hence if they should benefit from the public prestige of it, seems crucial when we consider the value and credit of science in modern society. In fact, that is the controversial demarcation problem and it must be noted that having strict positions in this context is claimed to be impossible at least philosophically (Nickles, 2006). However, as seen in this research, the cited difficulties in the issue of science versus pseudoscience can be possibly overcame to some extent if the approach of Smith and Scharmann (1999) is adopted to the context by rejecting the idea of strict demarcation and replacing the question of 'Is this field of research scientific or not?' by 'What are the features that make the field of research more scientific or less scientific?'. It was seen that candidate classroom teachers previously used the characteristics that dominantly based on the notion of being empirical and performed poorly in the process of concluding the status of knowledge claims. But after the intervention that based on pre-determined characteristics in line with the approach cited above was performed, the guided participants were seemed to reason more validly and able to evaluate the status of the cases they investigated for being scientific or not.

It is clear that it is not possible to define science in a simple way or draw the borders of science with strict lines. Whether science should take its place within the limits of science when we consider the value of science in the presence of community or how close these limits are is an important problem. Depending on the results of the 
research, it is likely to see that candidate teachers applied for the characteristics which are more suitable for the traditional conception of science in the process of decision making regarding the being scientific of a case. Similarly Metin, \& Ertepinar (2016) indicated that teacher candidates would have difficulties to transfer their understanding about science into other issues and although they were aware of the scientific process, they had difficulties to demarcate science from pseudoscience. However, the present study results indicate that their reasoning abilities increased when they were given some characteristics of science that the candidate teachers could apply in determining being scientific. Also, it is suggested that using pseudoscientific cases is a useful tool to promote critical thinking (De Robertis, \& Delaney, 2000; Metin, \& Ertepinar 2016). For this reasons, it is of crucial importance that the candidate teachers be made to perceive the sense of modern science in educational process and be taught the characteristics of science they could use in evaluating being scientific.

\section{References}

Afonsoa, A. S., \& Gilbert, J. K. (2010). Pseudo-science: A meaningful context for assessing nature of science. International Journal of Science Education, 32(3), 329-348.

Akerson, V. L., Buzzelli, C. A., \& Donelly, L. A. (2010). On the nature of teaching nature of science: preservice early childhood teachers' instruction in preschool and elementary settings. Journal of Research in Science Teaching, 47(2), 213-233.

Allchin, D. (1996). Points east and west: Acupuncture and comparative philosophy of science. Philosophy of Science, 63, 107-115.

Ayvacı, H. Ş., \& Er Nas, S. (2010). Fen ve teknoloji öğretmenlerinin bilimsel bilginin epistemolojik yapısı hakkındaki temel bilgilerini belirlemeye yönelik bir çalışma/ A study to determine science and technology teachers' basic knowledge about epistemological structure of scientific knowledge. Kastamonu Education Journal, 18(3), 691-704.

Bauer, H. H. (2001). Science or pseudo-science: magnetic healing, psychic phenomena and other heterodoxies. Chicago: University of Illinois Press.

Bogdan, R. C., \& Biklen, S. K. (2007). Qualitative research for education: An introduction to theories and methods. Boston: Allyn and Bacon.

Creswell, J. W. (2012). Educational research: Planning, conducting, and evaluating quantitative and qualitative research. Boston, MA: Pearson Education Inc.

De Robertis, M. M., \& Delaney, P. A. (2000). A Second Survey of the Attitudes of University Students to Astrology and Astronomy. Journal of the Royal Astronomical Society of Canada, 94, 112.

Derry, G. N. (1999). What science is \& How it works. NJ: Princeton University Press.

Dickhaus, S. M. (1999). Nature of science - introduction. Evolution \& the Nature of Science Institutes (ENSI). Retrieved from http://www.indiana.edu/ ensiweb/lessons/conptt.pdf. (accessed 7 September 2015).

Dilworth, C. (2006). The metaphysics of science: An account of modern science in terms of principles, laws and theories (2nd ed). Dordrecht, The Netherlands: Springer.

Feder, K. (2014). Frauds, myths, and mysteries: science and pseudo-science in archaeology. New York: McGraw-Hill.

Finn, P., Bothe, A. K., \& Bramlett, R. E. (2005). Science and pseudo-science in communication disorders: Criteria and applications. American Journal of Speech-Language Pathology, 14,172-186.

Francis, L. J., \& Robbins, M. (2007). Belonging without believing: A study in the social significance of Anglican identity and implicit religion among 13-15 year-old males. Implicit Religion, 7(1), 37-54.

Gauch, H. G. (2009). Science, worldviews and education. Science \& Education, 18, 667-695.

Gay, L. R., Mills, G. E., \& Airasian, R. (2006). Educational research: Competencies for analysis and applications (8th ed). Upper Saddle River, NJ: Pearson/Merrill/Prentice Hall.

Gillies, D. (1998). Philosophy of science in the 20th century: Four central themes. Oxford: Blackwell Publishers.

Hofer, B. K. (2000). Dimensionality and disciplinary differences in personal epistemology. Contemporary Educational Psychology, 25, 378-405.

Hurd, P. D. (1998). Scientific Literacy: New Minds for a Cahanging World. Science Education, 82, 407-416.

İrez, S. \& Turgut, H. (2012). Fen eğitimi bağlamında bilimin doğası. In Ö. Taşkın (ed.), Fen ve teknoloji ögretiminde yeni yaklaşımlar, 245-270. Ankara: Pegem akademi.

Jahoda, G. (1969). The psychology of superstition. Harmondsworth, England: Penguin.

Johnson, M., \& Pigliucci, M. (2004). Is knowledge of science associated with higher skepticism of pseudoscientific claims? American Biology Teacher, 66(8), 536-548.

Kallery, M. (2001). Early-Years Educators' Attitudes to Science and Pseudo-Science: The Case of Astronomy and Astrology. European Journal of Teacher Education, 24(3), 329-342. 
Laudan, L. (1983). The demise of the demarcation problem. In R. S. Cohen \& L. Laudan (Eds.), Physics, philosophy and psychoanalysis (pp. 111-127). Dordrecht: Reidel.

Lederman, N. G. (1998). The state of science education: Subject matter without context. Electronic Journal of Science Education, [On line], 3 (2), December. Retrieved from http://wolfweb.unr.edu/homepage/jcannon/ejse/ejsev3n2.html (accessed 25 March 2015).

Lindem, V. M. (2014). Charlatans in lab coats: how scientific communication can unmask pseudo-science. A Unpublishes master thesis. The Faculty of San Diego State University.

Losh, S. C. \& Nzekwe, B. (2011). Creatures in the classroom: Preservice teacher beliefs about fantastic beasts, magic, extraterrestrials, evolution and creationism. Science \& Education, 20(5-6), 473-489.

Losh, S., Tavani, C., Njoroge, R., Wilke, R., \& Mcauley, M. (2003). What does education really do? Skeptical Inquirer, 27, 30-35.

Lundström, M. (2007). Students' beliefs in pseudo-science. Paper presented at the European Science Education Research Association (ESERA) conference, Malmö, Sweden.

Mahner, M. (2007). Demarcating science from nonscience. In T. A. Kuipers (Ed.), General philosophy of science: Focal issues, 515-576. North Holland: Elsevier.

Martin, M. (1994). Pseudo-science, the paranormal, and science education. Science \& Education, 3, 357-371.

McComas, A. J. (1996). Skeletal muscle form and function. Champaign, IL: Human Kinetics.

Metin, D., \& Ertepinar, H. (2016). Inferring pre-service science teachers' understanding of science by using socially embedded pseudoscientific context. International Journal of Education in Mathematics, Science and Technology, 4(4), 340-358.

Moore, D. W. (2005). Three in four Americans believe in paranormal. Gallup Poll News Service (16 June 2005). Retrieved from http://www.gallup.com/poll/16915/Three-Four-Americans-BelieveParanormal.aspx (accessed 28 March 2009)

Mugaloglu, E. Z. (2014). The Problem of Pseudoscience in Science Education and Implications of Constructivist Pedagogy. Science \& Education, 23(4), 829-842.

Murcia, K., \& Schibeci, R. (1999). Primary student teachers' conceptions of the nature of science. International Journal of Science Education, 21(11), 1123-1140.

Nickles, T. (2006). Problem of demarcation. In S. Sarkar and J. Pfeifer (Eds.), The philosophy of science an encyclopedia, 188-197. New York: Routledge.

NSB (National Science Board). 2006. Science and engineering indicators - 2006. Arlington, VA: National Science Foundation.

Preece, P. F. W., \& Baxter, J. H. (2000). Scepticism and gullibility: The superstitious and pseudo - scientific beliefs of secondary school. International Journal of Science Education, 22(11), 1147-1156.

Republic of Turkey. Ministry of National Education [MEB]. (2013). Fen bilimleri dersi ögretim programi/ the science curriculum. Ankara.

Roth, W. M., \& Roychoudhury, A. (1994). Physics students' epistemologies and views about knowing and learning. Journal of research in Science Teaching, 31(1), 5-30.

Ryan, A.G., \& Aikenhead, G.S. (1992). Students' preconceptions about the epistemology of science. Science Education, 76, 559-580.

Ryder, J. (2001). Identifying science understanding for functional scientific literacy. Studies in Science Education,36 (1), 1-44.

Sagan, C. (1996). The demon-haunted world: science as a candle in the dark. New York: Ballantine.

Shermer, M. (1997). Why people believe weird things: Pseudo-science, superstition, and other confusions of our time. New York: W. H. Freeman and Company.

Smith, M. U., \& Scharman, L. C. (1999). Defining versus Describing the Nature of Science: A Pragmatic Analysis for Classroom Teachers and Science Educators. Science Education, 83(4), 493-509.

Sperandeo-Mineo, R. M. (2004). The pre service physics teacher education model implemented by the FFC research project involving \& Italian universities: guidelines and preliminary results. In M. Michelini (Ed.), Quality Development in Teacher Education and Training, 89-95. Udine, Italy: Lithostampa, Pasian di Prato.

Suchting, W. A. (1995). The nature of scientific thought. Science \& Education, 4, 1-22.

Sugarman, H., Impey, C., Buxner, S., \& Antonellis, J. (2011). Astrology beliefs among undergraduate students. Astronomy Education Review, 10(1).

Tobacyk, J. J. \& Milford, G. (1983). Belief in paranormal phenomena: Assessment instrument developed and implications for personality functioning. Journal of Personality and Social Psychology, 44, 1029-1037.

Tsai, C. C. (2002). Nested epistemologies: Science teachers' beliefs of teaching, learning and science. International Journal of Science Education, 24(8), 771-783.

Tseng, Y. C., Tsai, C. Y., Hsieh, P. Y., Hung, J. F., \& Huang, T. C. (2014). The relationship between exposure to pseudoscientific television programmes and pseudoscientific beliefs among Taiwanese university students. International Journal of Science Education, Part B, 4(2), 107-122. 
Turgut, H. (2009). Fen ve teknoloji öğretmen adaylarının bilimsel sözde-bilimsel ayrımına yönelik algıları/ Preservice Science Teachers' Perceptions about Demarcation of Science from Pseudoscience. Eğitim ve Bilim Dergisi/ Education and Science, 34(154), 50-68.

Turgut, H. (2011). The context of demarcation in nature of science teaching: The case of astrology. Science \& Education, 20, 491-515.

Turgut, H., Akçay, H. \& İrez, S. (2010). Bilim sözde-bilim ayrımı tartışmasının öğretmen adaylarının bilimin doğası inanışlarına etkisi/ the impact of the issue of demarcation on pre-service teachers' beliefs on the nature of science. Kuram ve Uygulamada Eğitim Bilimleri / Educational Sciences: Theory \& Practice, 10(4), 2621-2663.

Ulett, G. A., Han, J. \& Han, S. (1998). Traditional and evidence-based acupuncture: History, mechanisms, and present status. Southern Medical Journal, 91(12), 1115-1120.

Uslu, F. (2011). Bilimselliğin kriteri ve sınırları problemi - bilim, bilim olmayan ve sahte bilim -/ The Criteria of Science and Problem of Demarcation - Science, Non-Science and Pseudo-Science -. Hitit Üniversitesi Ilahiyat Fakültesi Dergisi/Journal of Divinity Faculty of Hitit University, 10(9), 5-35.

Walker, W. R., Hoekstra, S. J. \& Vogl, R. J. (2002). Science education is no guarantee for skepticism. Skeptic, 9(3), 24-28.

Wang, J. W. \& Lin, W. Y. (2005). Explanation effect in superstitious thinking. Chinese Journal of Psychology, $47(1), 39-60$.

\section{Author Information}

\section{Huseyin Es}

Sinop University

Education Faculty, Science Education Department

Korucuk Köyü No:35 57000 - Sinop / Turkey

Contact e-mail: huseyines@yandex.com

\section{Halil Turgut}

Sinop University

Education Faculty, Science Education Department

Korucuk Köyü No:35 57000 - Sinop / Turkey 